\title{
Peter Dyer: 'There is a big challenge in deciding how we fund clinical care'
}

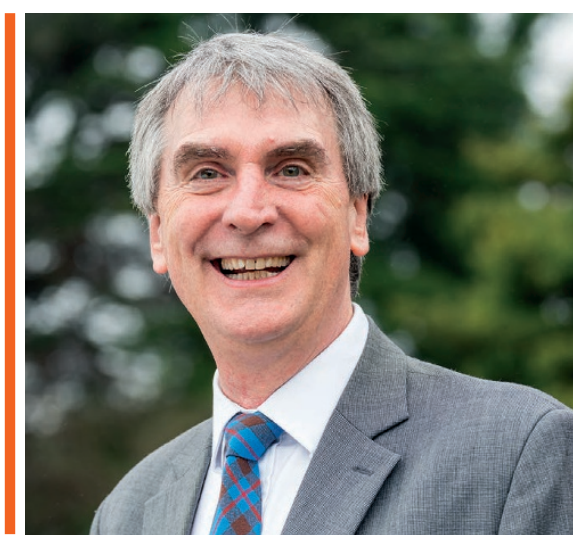

\section{Why did you become a dentist?}

I grew up in Lancaster where I used to go to the community dentist, called Keith Woods and he really got me interested in dentistry in the first instance. Throughout my fifth and sixth form, I used to go and sit with Keith and he gave me the chance to drill and fill extracted teeth. He was super.

Keith introduced me to Eric Cooper, a consultant in oral surgery, and it was really Eric who made me think I want to take this further. He was a giant in the dental world.

My dad was a doctor and he often said that he wished he had been a dentist because he'd finish work at 5 o' clock and when you're a doctor that doesn't happen. As it happened I ended up doing a career that never finished at 5 o' clock but that was my choice. The other thing my dad used to say to me was that the dentists have more fun than the doctors!

What led you to oral maxillofacial surgery?

I was working in Great Ormond Street

Hospital as a resident oral surgeon because at that stage I wanted to be a children's dentist, that was my great love. But when I was there we were doing a lot of cleft lip and palate work and I got interested in the surgery side of things. So with some encouragement from a consultant I worked with at UCH, Mr James, I decided to apply for medicine and worked my way through the surgical training, mostly in London

Ruth Doherty, Senior Managing Editor of the BDJ, interviews BDA President, Peter Dyer. Peter graduated in dentistry from the Royal Dental Hospital in 1979 and then qualified in medicine from University College Hospital, London in 1988. He was appointed consultant in oral and maxillofacial surgery to the University Hospitals of Morecambe Bay NHS Foundation Trust in 1998 with a special interest in trauma and orthognathics. As Chair of the Central Committee for Hospital Dental Services Peter was highly involved in the industrial action taken by trainee hospital dentists in 2016 .

but also in Bristol and Birmingham. I wasn't the 'great academic' - I had my ups and downs. For example, I missed my medical finals and had to do another six months, and had some episodes of not passing postgrad exams.

I've never encouraged anyone to do maxfax. And that's not because I didn't enjoy it! The reality is that it's a slog and you're working long hours when eventually you do get there. I often say to undergrads who want to do it, 'you do realise that throughout your twenties your friends will be going off on holidays, buying nice cars and socialising and you will be at a desk working, not making any money. Your whole life seems to shift by ten years.

There are more opportunities for young dentists nowadays that also allow you to have a life outside of dentistry and that is really important. I don't regret what I did for a minute but I think that it's really important that those interested in maxfax as a career are aware of the implications.

\section{Do you think the GDC should be more like the GMC?}

I really worry about 'blame culture'. Neither the medical nor dental professions have got away from that properly. I do think that the GMC is getting better at tackling this problem but the dental profession has some way to go.

Look at the airline industry, it's now absolutely open. Very few pilots get prosecuted or taken to court. If you make a mistake in that industry you tell people, because the next time that mistake is made by you, or somebody else, it's your life and the lives of the 300 people sitting behind you that are at stake. In the medical and dental professions we are still frightened to report mistakes.

This idea that you can't say sorry to somebody is a real problem. Thank goodness it is now a general directive from the GMC that saying sorry is not an admission of guilt because by talking to relatives and patients you start to diffuse most of the problems.

I don't think we'll ever solve completely the problem of defensiveness, but we need to get to a point where clinicians can be confident that they are not going to get hauled over the coals for small mistakes. The GMC has at last recognised that it is distressing for people going through this - some lose their livelihoods, families break down under the strain.

Now I think the GMC would be the first to admit they have not got there yet. But the current President's aim is to go from 3,000 investigations to 300 because he knows that actually there are a very small percentage of doctors who need investigating. And this is where I think the GDC could learn from the GMC.

Another area from which the GDC could learn from the GMC is keeping the annual retention fee at a modest amount. The GMC 
has somehow managed its finances in such a way that the ARF remains unchanged or only goes up very slightly.

Another thing we could take from the GMC is their success in keeping a doctor as their President; we've obviously lost that as a dental profession. I think dentists ought to be leading the profession.

\section{How do you feel about leading the BDA's first ever strike?}

My natural position is negotiation and I see myself as a peacemaker. However, when faced with this decision to take the strike to the BDA Principal Executive Committee as a proposal, it was an easy decision for me because it was the right decision. I was in no doubt about that whatsoever. I felt that we were up against an intransigent secretary of state, who on public record is someone who would see other alternatives to the NHS and I think that was coming across in his high handed attitude. Trainee doctors and dentists were recognising that this was the NHS which was under threat. This wasn't just about their working conditions; it was a much wider issue about a Government that was possibly destined to introduce privatisation at many different levels.

Sadly this is happening already - there is a lot of creeping privatisation in the hospitals and out in community healthcare. I am obviously aware that dentists do a lot of private work as well and I'm not criticising that at all. But what I am criticising is the stealth factor with regard to the privatisation of the NHS. I think we are losing something which is very precious. The whole thing around there not being enough money isn't true. We are a wealthy nation - it's about how we distribute it. It's a choice issue and the current administration is not choosing the NHS. And my worry is it won't matter which party is in power, there will be a slow erosion of the health service.

\section{Is the $\mathrm{BDA}$ uncomfortably close to the BMA?}

We need to have that debate with the membership and now is the right time to have it. The question that needs to be asked is 'can we now pull back some services from the BMA?' The BDA, because it knows dentists and dentistry, has the expertise to answer questions as well as the BMA, if not better, on some subjects.

I don't see it as an 'us and them' situation. There are areas where we will always work with the BMA; for example, for the DDRB (Review Body on Doctors' and Dentists'
Remuneration), a joint response is the right thing. But now it's time for a debate by the membership of the BDA, particularly in my committee - the Central Committee for Hospital Dental Services - about how we work together in the future.

There is a lot of concern that you need to have the BMA behind you, but actually we have the BDA behind us and they can do the job well!

\section{Will oral surgery ever be free from OMFS?}

The maxfax specialty (OFMS) has now made itself very much a medical, surgical specialty so the debate has to be had in the BDA about where that puts us in terms of oral surgery? It's very clear in my mind that oral surgeons are multi-disciplinary approach. But that doesn't make them better, it's just different.

I think one of the great opportunities for young dentists now is the chance to subspecialise in practice and hopefully under the auspices of the NHS, if the Department of Health can organise it. If I was starting out now I'd be looking to specialise, eg in perio or oral surgery, and finding some like-minded colleagues to set up in a building where I'm in one surgery and the endodontist is in the next, the restorative in the next and so on. We could then work as a team under one roof delivering a really good multidisciplinary service to patients via the NHS. That to me would be ideal.

When dental students say to me what is their future in dentistry? I say, get a

\section{'This idea that you can't say sorry to somebody as a clinician is a real problem.'}

dentists who have medical training but don't have a medical degree, and are competent to do a whole range of oral surgery. For me the key thing is the talent not the title. It doesn't matter whether they are called a maxfax consultant or an oral surgeon or whatever, as long as they are right person for that specification then they should be part of the team.

When I was medical director I was aware of what could only be described as clinical hypocrisy. From 9 am to $5 \mathrm{pm}$ a specialty and associate specialist (SAS) doctor might only work as an assistant to a consultant.

Then at 5 pm, a bit like Cinderella, something magical happened, the consultants went home and the SAS doctors were left responsible until 9 am the next morning. Why was it that the SAS doctors could suddenly run the hospital by themselves when in waking hours they couldn't? The key point is that the SAS doctors are a highly skilled, highly qualified, hard-working group and in oral surgery, we have to recognise that and the BDA ought to be standing up for them.

\section{How is a restorative consultant 'better' than a restorative specialist in a practice?}

They are absolutely not better. This is about doing a different type of work. The hospital consultant probably sees a different range of work. They might deal with cleft patients, hypodontia cases or patients with cancer rehabilitation where they have to work with both the surgeon and the orthodontist. The environment in the hospital is set up for that degree under your belt, then do your DF year, maybe get a bit of DCT experience in a hospital and then during that time decide what you want to do. Perhaps do an $\mathrm{MSc}$, and consider going overseas for this, and then, with that qualification, set up in practice somewhere with your colleagues. Opportunities for this are going to increase.

\section{Name three things being member of the} BDA has done for you...

1. It was so useful just to know that I could go and meet some colleagues via the BDA, for example, at a lecture or other event. In particular during my medical training, the BDA helped me to keep in touch with dentistry. This was a great support

2. The advice provided by the BDA has always been useful. For example, just after I qualified in dentistry in the early eighties, I worked for a year as a dentist. Very quickly I hit a problem because the chap I was working with, I now realise, had issues and the practice was falling apart. I was sometimes left by myself as a fairly newly qualified dentist for days on end and there were complaints, suppliers weren't being paid etc. Understandably, I got quite distressed about all this and I called the BDA for advice. They ascertained I didn't have a contract holding me there and so suggested I leave, which is what I did!

3. The BDA instilled this idea of being in a profession for me. I remember the day 
that we qualified, a few of us who had been on the BDA Student Committee, just came up and had a chat at 64 Wimpole St. It was almost like we needed to identify with the profession. I think that the BDA should and does symbolise the profession.

\section{How do you ensure the BDA works as an institution for new graduates?}

The millennial generation are transactional; I see that with my own kids. And that is not selfish, they just want to know what they get for an outlay. So maybe we need to slightly alter the membership structure so they can buy into something when they need it. We also always have to be a voice and be out there speaking up about and proactive in issues that are affecting young dentists.

I think that new graduates are part of a kinder generation - the way they are taught at school makes them much more self-aware. I see that with the UCLAN students now; they are self-aware, self-motivated and kind.
What is your advice to those who might be feeling a bit fed up with dentistry?

During a long career everyone is going to get dejected at some time. Nobody can keep up that momentum. I've had times where I've realised I've dipped a little. I think belonging to a professional organisation, such as the $\mathrm{BDA}$, is really important to combat this. The BDA has a big part to play via its networks.

Isolation, whether social or professional, is damaging to your health and also to your career. Sometimes you can become isolated without even knowing about it and that happened during my training. I was locked away, studying and it wasn't good for my health. I realised the balance was completely wrong. I was rushing home, putting something in the microwave to eat, taking two minutes to eat it and rushing upstairs to study. I failed twice in a row and I realised something had to change.

The BDA discusses social isolation and mental health issues quite a lot. Back in the

\section{'What I am criticising is the stealth factor with regard to the creeping privatisation of the NHS'}

I'm very optimistic about the dental profession because the people coming through are so talented.

What one thing would you regret not doing during your year as BDA President?

My regret would be if I don't make the most of the opportunity I have to speak to people about the importance of a profession and how we are better together. I want to go around and meet as many people as possible. I want to see students, I want to see old dentists, I want to see young dentists, I want to see practising dentists, to see specialist groups, people who are disaffected with the BDA... I want to hear any criticism people have because we have to face up to that.

The message I want to put out is that the professions are under threat now like they have never been before. Some may see professions as outdated and irrelevant today. However, I do think there is merit in the support network a profession can give and if you lose that it doesn't matter how many retweets you have or how many friends in your friendship circle online, if you are not meeting people face to face and you don't have that support, then you are missing something important. nineties you all had to be macho surgeons together. I think that macho culture is damaging to health. And it's only now that we, as a medical and dental profession, are starting to talk about these things. And I think that the Royals' initiative to raise attention around mental health is probably quite healthy because we have to talk about this more.

\section{What do you advise dentists to do if they do start to feel stressed or low?}

Being self-aware means you can better identify times when you need help. If you are aware that it's happening seek professional help quickly, absolutely. Don't be ashamed. My generation tended to go down the pub on a Friday night and that created its own viscous cycle, but in some ways maybe it was a bit better than being isolated at home.

I know a local GP and practice nurse in Lancaster and they both tell me they see a high instance of anxiety amongst students and they've noticed it going up and up. They put a lot of it down to mobile phones and the fact that students don't go out socialising quite as much now, so they don't build up resilience strategies.

In your practice, it's good to encourage your colleagues to be open. Sit down every month with your nurses and your receptionists so there is no hierarchy. Treat everyone as an equal, because quite often it's one of your colleagues who might be the one to point out that you're not yourself or pick up on patterns that may signify mental health issues.

\section{What are you most proud of?}

When I became a consultant in Morecambe Bay, I was building up a department and I interviewed quite a few potential staff to whom I asked that question. The answer I got from every single one of them was that they were proud of bringing up their children. I remember thinking that's an interesting answer but I thought they were going to say something else. I do actually understand that answer now, twenty years down the line having just retired with my kids heading off to university. I can absolutely understand that answer.

But from the professional side of things, I'm proud of the department we built up over the years. We were always recognised as a friendly team that gave patients a lot of time. None of the clinicians did any private work but were committed to the NHS. We used to have a hierarchical structure but now there is a flat structure with the chair of our regular departmental meeting rotating each month - with dental nurses, secretaries, receptionists, consultants, lab technician, all equal. We worked as a genuine team and that was recognised by dentists and doctors out in practice.

I think I'm most proud that I was a) able to go back to my home area, but b) that I was able to work in a team that had the same values in the NHS as I stood for. I am well aware that one's legacy disappears quite rapidly and I'm not bothered about that now that I've retired. The point is that over 20 years we built up a good team and it was a good service.

\section{What do you feel are the biggest challenges} in dentistry for the future?

I believe there is a big challenge in deciding how we as a society want to fund clinical care. We have to recognise that there are forces at work that aren't necessarily operating in our best interest. Much of this is covered up in 'safety' and giving 'ownership' to clinicians and patients. It's a lot of words but the reality is there is a lot of dismantling by stealth of the NHS and it will be a big challenge to combat that. 